National Marine

Fisheries Service

NOAA
Fishery Bulletin

as established in 1881 ๙
Spencer F. Baird

First U.S. Commissioner of Fisheries and founder of Fishery Bulletin
Abstract-Underwater vehicles have many advantages for sampling fish; however, estimates can be biased by behavioral responses to sampling gear. To evaluate avoidance and attraction bias we assessed changes in fish abundance relative to a variety of sampling vehicles during transit through a test bed. Fish species were classified into five attraction and avoidance categories according to the behavioral responses exhibited. We observed that the rigor of behavioral responses varied by vehicle, vehicle range and altitude, transect number, and habitat complexity. The effect of each variable is dependent on behavioral guild, but vehicle range was the most consistent predictor of changes in abundance regardless of vehicle. Vehicles that surveyed the environment at higher relative altitudes off the seafloor and at slower speeds elicited weaker behavioral responses regardless of whether those reactions were attraction or avoidance. The testbed approach allowed assessment of responses that cannot be observed from the perspective of a sampling vehicle but was restricted by the number of species-specific interactions observed. Despite success in estimating behavioral responses, calibrating the effect against known densities of fish was not possible. However, the method used is a robust way for future investigations to quantify species-specific responses for gear calibration and to provide information that aids in the calculation of fish abundance.

\title{
Assessment of attraction and avoidance behaviors of fish in response to the proximity of transiting underwater vehicles
}

\author{
Matthew D. Campbell (contact author) ${ }^{1}$ \\ Ariane Huddleston ${ }^{2}$ \\ David Somerton (retired) ${ }^{3}$ \\ M. Elizabeth Clarke ${ }^{4}$ \\ Waldo Wakefield (retired) ${ }^{5}$
}

\author{
Steve Murawski ${ }^{6}$ \\ Chris Taylor ${ }^{7}$ \\ Hanumant Singh ${ }^{8}$ \\ Yogesh Girdhar ${ }^{9}$ \\ Mary Yoklavich (retired) ${ }^{\mathbf{1 0}}$
}

Email address for contact author: matthew.d.campbell@noaa.gov

${ }^{1}$ Mississippi Laboratories

Southeast Fisheries Science Center

National Marine Fisheries Service, NOAA

3209 Frederic Street

Pascagoula, Mississippi 39567

${ }^{2}$ Science and Technology Center

Northern Gulf Institute

Mississippi State University

1021 Balch Boulevard

Stennis Space Center, Mississippi 39529

${ }^{3}$ Resource Assessment and Conservation Engineering

Alaska Fisheries Science Center

National Marine Fisheries Service, NOAA

7600 Sand Point Way NE, Building 4

Seattle, Washington 98115

${ }^{4}$ Northwest Fisheries Science Center National Marine Fisheries Service, NOAA

2725 Montlake Boulevard East

Seattle, Washington 98112

${ }^{5}$ Newport Research Station

Northwest Fisheries Science Center

National Marine Fisheries Service, NOAA

2032 SE OSU Drive

Newport, Oregon 97365-5275
${ }^{6}$ College of Marine Science University of South Florida 140 Seventh Avenue South Marine Science Laboratory 118 St. Petersburg, Florida 33701

${ }^{7}$ Center for Coastal Fisheries and Habitat Research

National Center Coastal Ocean Sciences National Ocean Service

101 Pivers Island Road

Beaufort, North Carolina 28516

${ }^{8}$ Department of Electrical and Computer Engineering

Northeastern University

360 Huntington Avenue

Boston, Massachusetts 02115

${ }^{9}$ Deep Submergence Laboratory

Woods Hole Oceanographic Institution

266 Woods Hole Road

Woods Hole, Massachusetts 02543-1050

${ }^{10}$ Fisheries Ecology Division

Southwest Fisheries Science Center

National Marine Fisheries Service, NOAA

110 McAllister Way

Santa Cruz, California 95060
Manuscript submitted 18 February 2021. Manuscript accepted 13 September 2021. Fish. Bull. 119:216-230 (2021).

Online publication date: 1 November 2021. doi: 10.7755/FB.119.4.2

The views and opinions expressed or implied in this article are those of the author (or authors) and do not necessarily reflect the position of the National Marine Fisheries Service, NOAA.
High-relief, complex seafloor habitats (e.g., rock and coral reef) present a number of challenges for the deployment of traditional fishing gears, such as seines, gill nets, bottom trawls, and longlines. These habitats are rugged, are prone to snag and destroy sampling gear, and are often damaged by sampling gear (Hall-Spencer et al., 2002; Mangi and Roberts, 2006; Roberts et al., 2006). Further, gears such as traps and handlines have been used to sample populations of reef fish species, but their size selectivity limits their utility to a few species and to a narrow range of size and age composition (Parker et al., 2016). Because of these difficulties, the use of optical gears mounted on underwater stationary platforms and on vehicles are becoming increasingly common in efforts to sample complex reef environments (Yoklavich et al., 
2007; Patterson et al., 2009; Armstrong and Singh, 2012; Grasty, 2014; Bacheler and Shertzer, 2015). Attractive aspects of optical sampling gears include that they 1) do not require extraction of fish, 2) have negligible impact on the habitat, 3) collect habitat data, and 4) often allow calculation of sampling volume or area and therefore can be used to produce habitat-specific density estimates that can be scaled to calculate abundance (Royle et al., 2009; Trenkel and Lorance, 2011; Whitmarsh et al., 2017).

An artifact of many fisheries survey methods is that the unit of measurement is an observation rate or catch rate and therefore cannot be used to estimate fish densities (e.g., fish per unit area). Collection of rate data constrains analysts to development of relative abundance indices (Williams et al., 2018) that are rarely calibrated against known fish densities and therefore cannot provide data to calculate absolute abundance. In addition, gear bias can affect counts; for example, observations and counts of fish are negatively affected during scuba-diver surveys because of air bubbles from exhalation (Gray et al., 2016; Emslie et al., 2018). Using vehicles to conduct optical surveys is a popular sampling method because they can cover long distances while transiting, allowing estimation of area sampled and fish densities, but they too will have inherent sampling biases (Clarke et al., 2009; Stierhoff et al., 2013; Thanopoulou et al., 2018).

Estimates of fish densities are useful because they can be scaled over the area of known habitat to calculate absolute abundances for use in stock assessments (O'Connell and Carlile, 1993; Yoklavich et al., 2007). Although calculation of fish density might seem like a straightforward process, estimates can be affected by environmental conditions and fish behavior (Fig. 1).

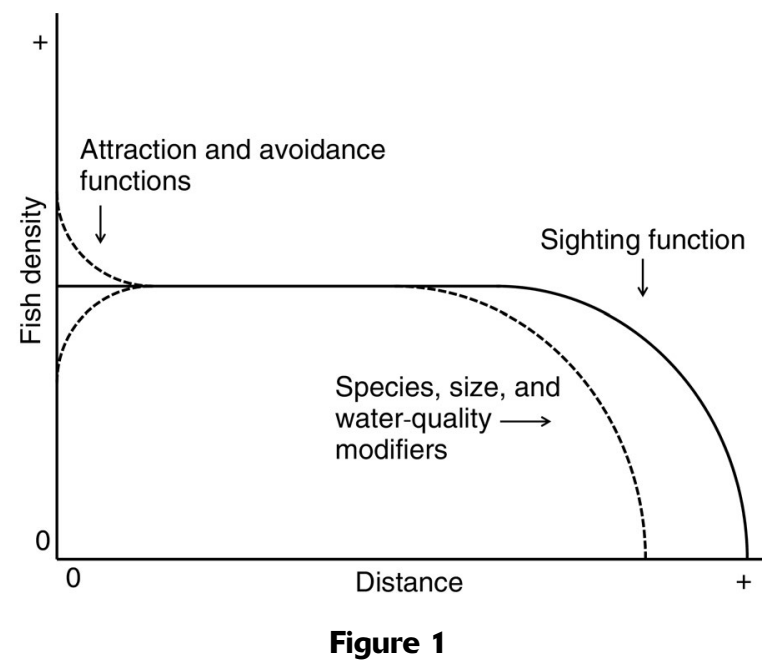

Diagram showing the theoretical effects of attraction and avoidance (dashed line above the sighting function) and sighting (solid line) functions on density estimation. The dashed line under the sighting function represents how fish density is theoretically modified by water quality, species, and size of the individuals observed.
Therefore, it is critical to estimate sighting functions and attraction and avoidance functions when conducting distance sampling and strip-transect surveys (Sale and Sharp, 1983; Ensign et al., 1995; Cheal and Thompson, 1997). Importantly, the need for estimating such functions has been shown to be true even for species with minimal or no avoidance behaviors (Kulbicki and Sarramégna, 1999).

As with any sampling gear, fish are likely to respond to the presence of stationary platforms and vehicles, and those responses have been recognized as a potential source of bias (Uzmann et al., 1977; Jagielo et al., 2003; Stoner et al., 2008). Each of these vehicles has its own characteristics related to movement speed, deployment altitude, acoustic signature, size, and visibility, all of which can introduce bias into the data collected (Koslow et al., 1995; Lorance and Trenkel, 2006; Stoner et al., 2008). In addition, fish are apt to respond to novelties in the environment in different ways in accordance with survival and foraging needs (Olla et al., 1998) and perhaps out of curiosity. Regardless of the underlying motivation, species-specific responses to sampling gears need to be quantified in order to deal with underlying biases and to generate reliable count, density, and abundance estimates.

Classes of vehicles commonly used in marine research include remotely operated vehicles (ROVs), autonomous underwater vehicles (AUVs), towed vehicles (TVs), and human occupied vehicles. Vehicles are used in sampling efforts predominately as part of line-transect methods, but the engineering specifications of vehicles and the execution of the line-transect surveys differ. These vehiclespecific differences can result in measurement biases of unknown direction and magnitude, the result of which is a need for gear calibration (Clarke et al., 2009). Further, it is recognized that, within a vehicle class, there will likely be many variations and exceptions (Yoklavich et al., 2015). Potential stimuli that could elicit attraction to, or avoidance of, vehicles include transit speed and altitude, visual profiles, and acoustic signatures. Ideally the specific stimuli causing a reaction can be identified, but more importantly fish responses in general need to be evaluated and quantified as a first step in understanding how to develop gear-calibration methods.

Because of the elevated interest in the use of vehicles to conduct surveys of high-relief, complex bottom types, the National Marine Fisheries Service (NMFS) initiated the Untrawlable Habitat Strategic Initiative (UHSI) in 2014. Participants in the UHSI were tasked with designing a multitiered field experiment to evaluate the sampling efficiency of camera systems mounted on stationary platforms, ROVs, AUVs, and TVs used to count fish and invertebrates in a sampling area or volume. The analysis in this study was focused on the change in abundance of reef fish species in a sampling volume due to the passage of a mobile survey vehicle. Our intent was to develop a functional relationship between vehicle range from the sampling volume and relative change in fish abundance (Fig. 1). 


\section{Materials and methods}

\section{Study area}

The experiment was conducted in August 2014 and in July and August 2015 at the Florida Middle Grounds, on the West Florida Shelf in the northeastern Gulf of Mexico (GOM) between Cape San Blas and Tampa Bay, Florida (Fig. 2). The Florida Middle Grounds consist of high-relief outcrops of carbonate rock (relief $\sim 2-5 \mathrm{~m}$ ) that host diverse assemblages of alcyonarian corals, sponges, and macroalgae (Austin and Jones, 1974; Darcy and Gutherz, 1984; Rezak et al., 1985; Koenig et al., 2000). The Florida Middle Grounds are the center of a productive snapper-grouper fishery of the eastern GOM and also host a diverse assemblage of pelagic and demersal fishes (Pierce and Mahmoudi, 2001). Water clarity in summer months ranges between 10 and $30 \mathrm{~m}$, and the depth range on the bank is 20-40 m (Koenig et al., 2000). Sampling depths ranged from 20 to $35 \mathrm{~m}$, and sites were selected to maximize natural light and clear water to ensure quality photography and accurate fish identifications and measurements. At the beginning of the experiment, low-relief $(1-3 \mathrm{~m})$ reef sites were selected to ensure safe deployment of the sampling gear. As our ability to accurately position sampling gear improved with time and safe vehicle transits could be ensured, we deployed them on increasingly complex highrelief habitat $(>3 \mathrm{~m})$.

\section{Platforms and deployment}

To evaluate the response to vehicles, we deployed an array of 3 stationary, autonomous camera platforms (Fig. 3) that remained on the seafloor between 7 and $10 \mathrm{~h}$ at multiple sites. The stationary platforms consisted of the Modular Optical Underwater Sampling System (MOUSS) (Amin et al., 2017) outfitted with the following components: stereo cameras, long-baseline (LBL) sonar beacons, and batteries (hereafter referred to as MOUSS platforms). The MOUSS platforms were fabricated with stainless steel and ballasted by the weight of batteries, pressure housings, and lead weights. Optical data were collected with the stereo cameras, which were capable of measuring and positioning objects in 3 dimensions (Amin et al., 2017). Cameras were mounted on a base-bar with an $80-\mathrm{cm}$ separation between cameras, at a $10^{\circ}$ "toe-in" angle, and

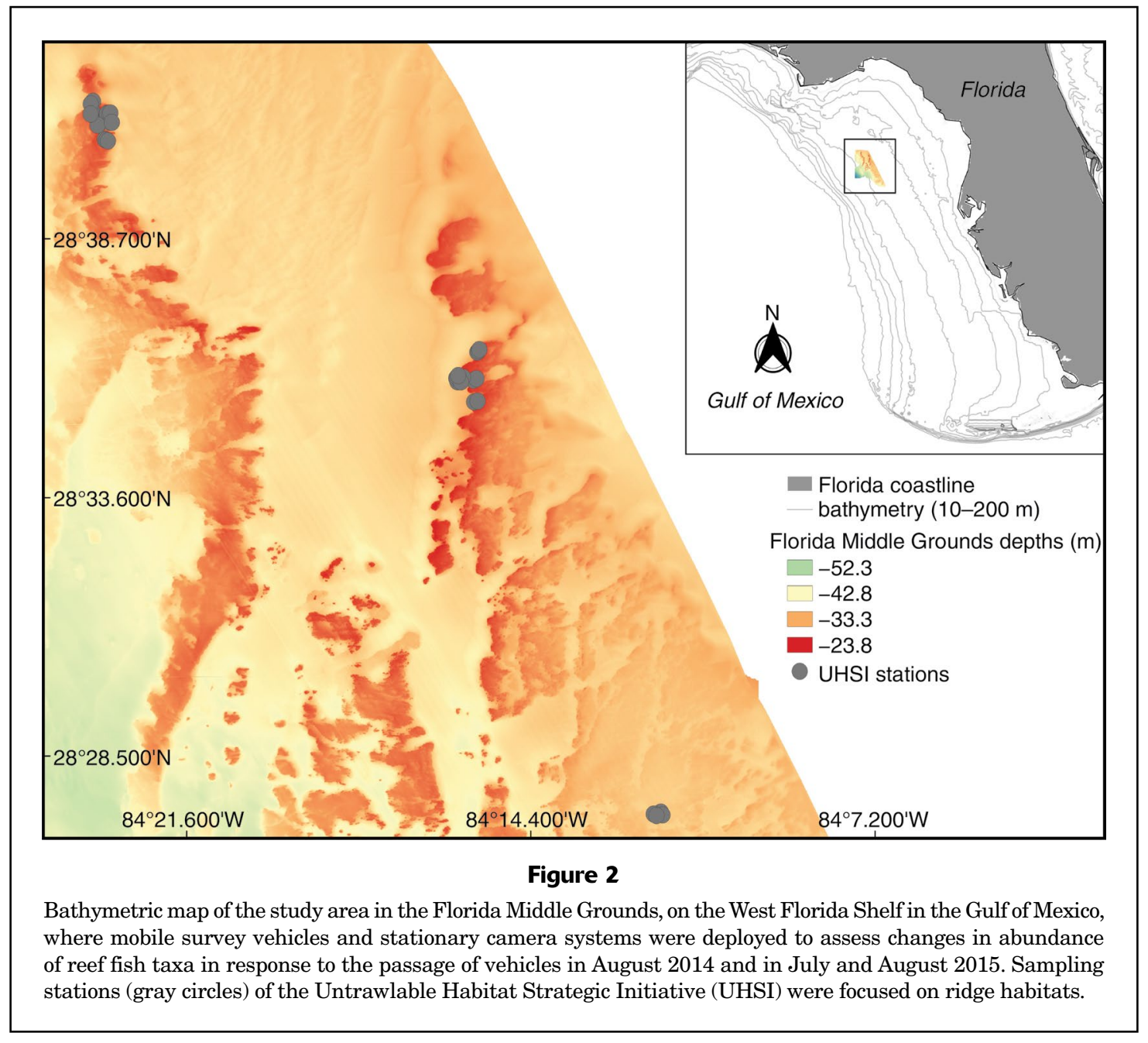




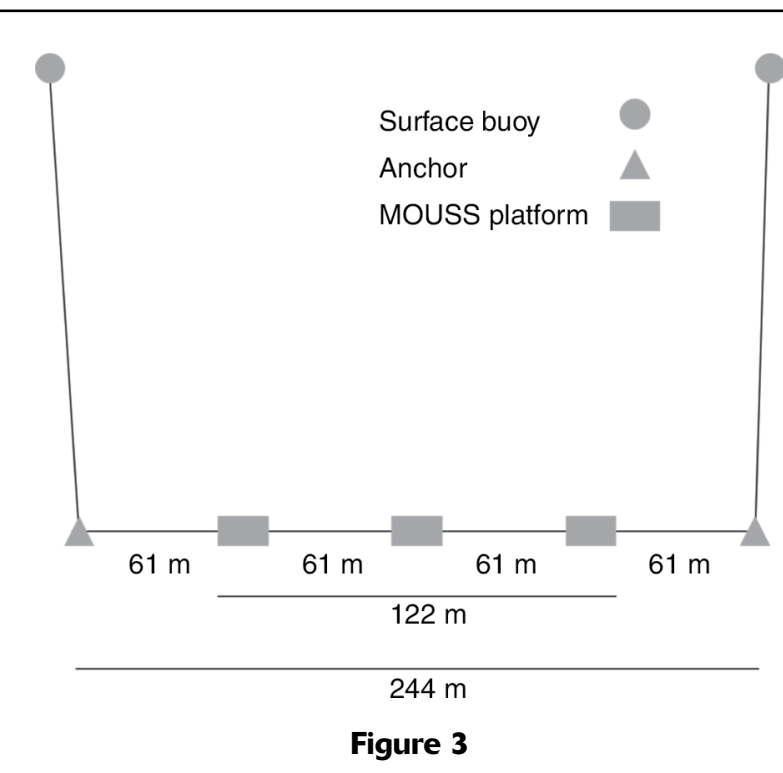

General schematic of 3 ground-tended Modular Optical Underwater Sampling System platforms (rectangles) set $61 \mathrm{~m}$ apart along a groundline. Anchors (triangles) and surface buoys (circles) were attached $61 \mathrm{~m}$ from the platforms at each end of the line. Total length between anchors was $244 \mathrm{~m}$, and the total distance between end cameras was $122 \mathrm{~m}$.

were $18 \mathrm{~cm}$ above the seafloor. Cameras have a $70^{\circ}$ field of view (FOV) and use ambient light, and camera settings were optimized for expected light conditions in clear, shallow water $(20-40 \mathrm{~m})$. Still images were acquired at a rate of 5 frames per second and were later processed to make video files in MPEG format. Geographic position of each platform was determined by using repeated acoustic surveys that triangulated the LBL acoustic beacons, and those positions were used to aid navigation of each vehicle in front of the MOUSS platforms.

To ensure that the orientation of each of the 3 MOUSS platforms was consistent, they were deployed in a fashion similar to that of demersal longline traps, such as those used in the sablefish (Anoplopoma fimbria) fishery in U.S. waters (Afanasyev et al., 2014) (Fig. 3). Platforms were attached to a $9.5-\mathrm{mm}$ bottom line that was continuously spooling off a winch while the ship maintained a constant heading during setting. The entire set was anchored on each end by steel weights $(22 \mathrm{~kg}$ ) located $61 \mathrm{~m}$ from the 2 outermost platforms. Two quick links were spliced into the longline at predetermined points $61 \mathrm{~m}$ apart, onto which the platforms were attached with high-strength snap shackles that were connected to platform harnesses. Anchor to anchor, the transect distance was $244 \mathrm{~m}$, and the distance between end point cameras was $122 \mathrm{~m}$ (Fig. 3). This method of deployment allowed the main line to act as a yoke to keep the MOUSS platforms, and therefore camera orientation, roughly perpendicular to the ship's bearing. Cameras were normally deployed in $~ 30 \mathrm{~min}$, and then the LBL beacons were surveyed to triangulate MOUSS platform position over a period that was typically $2-3 \mathrm{~h}$. The deployment and triangulation process provided time for fish to become acclimated to the presence of the MOUSS platforms prior to the deployment of the survey vehicles.

\section{Vehicles and transects}

Survey vehicles evaluated in the experiment included a Phantom HD2 $+2^{1}$ ROV (Deep Ocean Engineering, San Jose, CA), the Camera-based Assessment Survey System TV (Lembke et al., 2017), and the SeaBED AUV (Singh et al., 2004). For simplification we refer to the vehicles we used as $R O V, T V$, and $A U V$. Each vehicle has different deployment and operation properties that limited our ability to stage all vehicles simultaneously on the survey ship and to deploy all vehicles in a single day. Therefore, the survey was divided into 2 segments that were conducted back to back. As a result, general deployment areas could be surveyed with each vehicle, but exact locations were not replicated across survey legs, resulting in each vehicle operating in somewhat different habitats (i.e., depth, substrate type, and fish community and abundance varied by site). Thus, models used to evaluate fish responses were somewhat vehicle specific.

The ROV $(140 \times 69 \times 66 \mathrm{~cm}$, in length, width, and height, respectively) was constantly tethered to the ship to provide power for vehicle operations and was remotely piloted from the ship by using a combination of 2 live-feed cameras (front and rear), sector scanning sonar, and a compass. During ROV deployments, the ship was anchored and, as a result, no tether management system was required and the tether was sufficiently long $(338 \mathrm{~m})$ to navigate from anchor to anchor at all operational depths during the experiment. Following ROV launch, the vehicle was driven on the surface to the closest down-current buoy, and then the ROV descended to the anchor. Upon reaching the seafloor, the pilot oriented the ROV on the desired transect heading and parked the ROV on the seafloor for $15 \mathrm{~min}$ prior to beginning to survey the first transect. Transects were run parallel to the orientation of the 3 MOUSS platforms and camera FOV, from anchor to anchor in both directions, and with 15-min resting periods between each transect. Depending on sea state and time of day, 2-6 transects were surveyed at each site prior to recovery of the vehicle.

The TV $(179 \times 127 \times 87 \mathrm{~cm}$, in length, width, height, respectively) was towed behind the ship by using a winch and conducting wire that also powered the vehicle and provided real-time seafloor imagery to assist the pilot in navigation. Vehicle operations were conducted by a pilot who communicated with the ship's officers on the bridge about preferred heading and speed, and with deck personnel regarding winch payout and vehicle altitude.

\footnotetext{
${ }^{1}$ Mention of trade names or commercial companies is for identification purposes only and does not imply endorsement by the National Marine Fisheries Service, NOAA.
} 
Real-time vehicle altitude data and seafloor depths from the shipboard echo sounders are necessary to appropriately control the vehicle and avoid obstacles. Live views from the vehicle are provided by forward- and sidefacing cameras (AVT Prosilica GT1920, Allied Vision Technologies GmbH, Stadtroda, Germany) mounted at $35^{\circ}$ angles and constantly lit with LED flood lights. Cameras collected images at a resolution of $1936 \times 1456$ pixels and at 12 frames per second. The vehicle collected real-time hydrological (e.g., salinity, temperature, and depth), vehicle altitude, and compass data that were stored in onboard computers. Transects were surveyed in parallel to the set direction of the MOUSS platforms and perpendicular to the camera FOV. Between transect runs, the vehicle altitude was increased to a safe height, and the vehicle then was towed in a large oval. Therefore, during surveying of transects, the TV always traveled in the same direction down the transect line with $\sim 30$ min elapsed time between each transect.

The AUV $(1.90 \times 0.34 \times 1.50 \mathrm{~m}$, in length, width, and height, respectively) operated free from the ship at all times during a dive, following a preprogrammed route. The AUV was equipped with onboard power, computing, acoustic beacons, and an acoustic Doppler profiler for bottom-tracking, conducting its operations, and navigating through the environment. The vehicle's stereo cameras were oriented to photograph the seafloor (i.e., downward facing) and coupled with a xenon camera strobe to capture imagery during transit. Environmental data (e.g., salinity, temperature, depth) and vehicle altitude and position data were collected and stored onboard the AUV. At the start of the mission, the AUV descended to the seafloor, navigated to the programmed transect start position, and transited the desired course. Transects were surveyed parallel to the set direction of the MOUSS platforms and at a preprogrammed constant altitude above the seafloor (either 2 or $4 \mathrm{~m}$ ), in both directions, and at increasing distances from the camera with each successive transect. In 2014 , to ensure the vehicle was observed with the MOUSS platforms, vehicle altitude was lowered to $2 \mathrm{~m}$; therefore; vehicle altitude varied between sites although altitude during a dive was held constant. Each successive transect was separated by an interval of approximately $30 \mathrm{~min}$ from the previous transect, similar to the intervals used for surveys conducted with the TV.

Vehicle range from the MOUSS platform was calculated by using stereo-camera imagery data when the vehicle was observed and then by fitting a linear model to estimate values when the vehicle was outside of the MOUSS sampling volume. During vehicle passage, 5 vehicle position coordinates per second were measured in centimeters from the stereo-camera origin. We then used the point cloud positional data and a linear model to estimate vehicle position for periods when the vehicle was outside of the stereo-camera FOV. Positional data were then used to estimate vehicle range relative to when the vehicle passed across the $y$ intercept of the cameras (i.e., where $x=0$ ) for each second from $1.03 \mathrm{~min}$ before and after that moment (i.e., up and down range from the camera origin). This linear model assumes that the vehicles transited in a relatively straight line and that error in position estimates was reduced by obtaining estimates for positions of 5 data points per second. Therefore, the total time for video annotation was $2.06 \mathrm{~min}$. This time frame was selected because the fastest vehicle (the TV) transited across the stereo-camera FOV in $8 \mathrm{~s}$ and because abundance estimates from the MOUSS platforms were collected in 4-s bins.

In this way, several bins of count data can be captured during the time when the vehicle was just entering, within, or just departing the MOUSS platform sampling volume (i.e., the coincident sampling volume). Sometimes MOUSS platforms landed on uneven seafloor and were tilted in various orientations; as a result, measuring exact altitude of the vehicle during transit was not always possible. Therefore, we collected qualitative data as a measurement of vehicle transit altitude in lieu of measuring exact transit altitude. Qualitative vehicle altitude above the seafloor (RVA) was qualitatively ranked as low ( 1-2 m; code: 1$)$, middle ( 2-5 m; code: 2 ), and high ( $>5 \mathrm{~m}$; code: 3 ).

\section{Video annotation and relative abundance}

Fish were identified to the lowest taxon possible, and attraction and avoidance patterns relative to the vehicle were noted. When there were fewer than 50 individuals of a species in a given video frame all individuals were counted. When there were $>50$ fish, the total number was estimated by subsampling a portion of the school and extrapolating the subsample by the total area the school occupied on the video screen.

Videos were annotated in 2 different ways to test the following: 1) fish acclimation to stationary cameras after first deployment and 2) change in relative fish counts in relation to vehicle passage. To evaluate fish acclimation during the first hour of deployment, 2-min intervals were randomly selected from the first hour of MOUSS platform deployment and prior to vehicle deployment. Speciesspecific fish counts during this time were estimated in 4-s bins. To analyze fish response to mobile vehicles, speciesspecific fish counts were collected at 4-s intervals during a 2.06-min video segment for which the midpoint is defined as the video frame when the vehicle crossed the stereocamera origin. Depending on vehicle speed, this method resulted in fish counts for $1 \mathrm{~min}$ prior to and following vehicle transit, with a 4 -s interval when the vehicle passed directly in front of a MOUSS platform. The video frames in which the vehicle was captured with the stereo cameras were considered the coincident sampling volume, and the exposure time in the sampled volume was dependent on vehicle speed. Because speed varied by vehicle and condition, we excluded time as a factor in the models in favor of estimating vehicle range to the coincident sampling volume.

With a few exceptions, such as greater amberjack (Seriola dumerili), scamp (Mycteroperca phenax), and gray snapper (Lutjanus griseus), specific species were infrequently captured in images coincident to vehicle transit. 
Thus, developing species-specific models was not possible for most species observed; however, general attraction and avoidance response behaviors were easily characterized. As a result, species were grouped into 5 behavioral guilds, and abundance data from the species belonging to those groups were pooled for analysis (Table 1). Behavioral guilds identified and analyzed included pelagic pursuers, benthic pursuers, down movers, lateral movers, and local reactive. Group composition is shown in Table 1 but in brief was as follows: the pelagic pursuers were composed of jacks (Carangidae) and mackerels (Scombridae); the benthic pursuers were composed of groupers (Serranidae) and wrasses (Labridae); lateral movers were composed of snappers (Lutjanidae) and porgies (Sparidae); down movers were composed of species of damselfish (Pomacentridae) and jawfish (Opistognathidae); and the local reactive guild was composed of species of filefish (Monacanthidae), butterflyfish (Chaetodontidae), and sand perch (Diplectrum spp.). Fifteen models were produced for each unique combination of the 3 vehicles and 5 behavioral guilds.

Changes in fish counts during the MOUSS platform acclimation time were evaluated by using generalized additive models (GAMs) with the GAM predict function of the package mgcv (vers. 3.6.1; Wood, 2011) in $R$ (vers. 4.0.3; R Core Team, 2020). Fish acclimation models included the following variables: time (seconds) and habitat complexity (qualitatively rated 1-5 from low to high). Changes in relative abundance due to vehicle passage were also analyzed by using GAMs. Because all vehicles did not necessarily transit through equivalent transects (the TV and AUV had no shared transects), and therefore did not pass through equivalent underlying fish densities, changes were analyzed in separate models for each vehicle type (i.e., we did not create a single model with a vehicle variable). Additionally, the habitat complexity variable allowed us to model site-specific differences in abundance that could potentially mask responses to a vehicle. For example, without a variable that explains site-specific differences, high-abundance sites could potentially have disproportionate effects on outcomes. Models used to examine fish responses to vehicle passage included the following variables: RVA (low, middle, and high), transect number (integer), range (meters), and ranked habitat complexity (qualitatively rated 1-5 from low to high). Deployment of the entire transect course took significant effort. Thus, multiple transects were surveyed over the course of a day, and that daily number of transects was tracked as a sequential value called transect number. Transect number therefore is used to compile the total number of vehicle exposures that occurred on the transect course over a single deployment of the 3 MOUSS platforms on the transect course.

\section{Table 1}

Behavioral guild assignments based on movements of fish taxa in response to presence of mobile survey vehicles deployed in the Florida Middle Grounds during August 2014 and July and August 2015.

\begin{tabular}{lll}
\hline Pelagic pursuers & Benthic pursuers & Down movers \\
\hline Seriola dumerili & Mycteroperca venenosa & Pomacentridae \\
Sphyraena barracuda & Mycteroperca phenax & Pomacentrus sp. \\
Seriola rivoliana & Mycteroperca sp. & Chromis insolata \\
Carangidae & Epinephelus morio & Chromis enchrysura \\
Seriola sp. & Serranidae & Chromis sp. \\
Caranx lugubris & Halichoeres bathyphilus & Opistognathus aurifrons \\
Scombridae & Halichoeres bivittatus & Opistognathus sp. \\
& Halichoeres sp. & \\
& & \\
Lateral movers & Local reactive & \\
\hline & & \\
Rhomboplites aurorubens & Monacanthus ciliatus & \\
Lutjanus griseus & Stephanolepis hispidus & \\
Lutjanus campechanus & Monacanthus sp. & \\
Calamus calamus & Monacanthus tuckeri & \\
Calamus nodosus & Stegastes leucostictus & \\
Calamus penna & Stegastes partitus & \\
Calamus proridens & Stegastes sp. & \\
Calamus sp. & Stegastes variabilis & \\
Haemulon plumierii & Chaetodon ocellatus & \\
Haemulon sp. & Chaetodon sedentarius \\
Pagrus pagrus & Chaetodon sp. & \\
Clepticus parrae & Diplectrum formosum & \\
& Decodon puellaris & \\
\end{tabular}




\section{Results}

\section{General observations}

The array of 3 MOUSS platforms was deployed during daylight hours at 13 distinct areas over $9 \mathrm{~d}$ in August 2014 and at 7 distinct areas over $5 \mathrm{~d}$ in July and August 2015. Deployments of MOUSS platforms varied in time from 7 to $10 \mathrm{~h}$. Over the $9 \mathrm{~d}$ of dedicated sampling in 2014, 73 transects were surveyed with vehicles, resulting in 218 individual passes or observations in front of the MOUSS platforms. Over the $7 \mathrm{~d}$ of dedicated sampling in 2015,57 transects were surveyed with vehicles, resulting in 171 individual passes or observations in front of the MOUSS platforms.

The target speed of the AUV was $1.0 \mathrm{kt}(0.51 \mathrm{~m} / \mathrm{s})$, and target altitude was either 2 or $4 \mathrm{~m}$. In 2014, to improve the likelihood of observing the AUV in images from the stereo camera, the transect altitude was lowered from 4 to $2 \mathrm{~m}$. The AUV transited in straight lines but was vulnerable to heavy currents, which caused the vehicle to "crab," make frequent course corrections, and to transit at a more variable rate of speed. The target speed of the TV was approximately $3.5 \mathrm{kt}$ at an altitude of $2 \mathrm{~m}$, but sometimes the speed was as high as $5 \mathrm{kt}$ when travelling down current and the altitude was as high as $\sim 5 \mathrm{~m}$ in highrelief areas where the potential of hitting the reef was a concern. Because the TV is towed and control of the vessel is fairly precise at the surface (e.g., GPS navigation), the TV transited the straightest transects of all the vehicles. However, transect deployments had to be well planned and executed in order to avoid hitting obstacles (e.g., tending buoys or reef). The target speed and altitude of the ROV was $0.5-1.0 \mathrm{kt}$ and $0.5-1.0 \mathrm{~m}$ above the seafloor, but sometimes speed was as high as $2 \mathrm{kt}$ and altitude was as high as $2.5 \mathrm{~m}$ because of currents, tether orientation, and operator error. Currents, tether orientation, and pilot error sometimes caused the transect path to meander from the intended straight line. In general, the ROV was the vehicle most consistently observed on MOUSS cameras, and transects improved over time likely as a result of a combination of slow speeds and rapid feedback to the pilot.

\section{Generalized additive models}

Results from the fish acclimation GAMs indicate significant effects for both time and habitat complexity. The model explained $17.8 \%$ of deviance with a coefficient of determination $\left(r^{2}\right)$ of 0.11 . Although the information on model fit indicates that there is considerable unexplained variability, the trend indicates that fish counts declined during the acclimation period and reached an asymptote at around $45 \mathrm{~min}$ (Fig. 4). General observations indicate that jacks (Seriola spp.) and great barracuda (Sphyraena barracuda), when present, closely examined the stationary camera but lost interest quickly. In addition, the reef fish community observed immediately around the stereo cameras became more active at initial deployment but appeared to slowly become disinterested and begin to

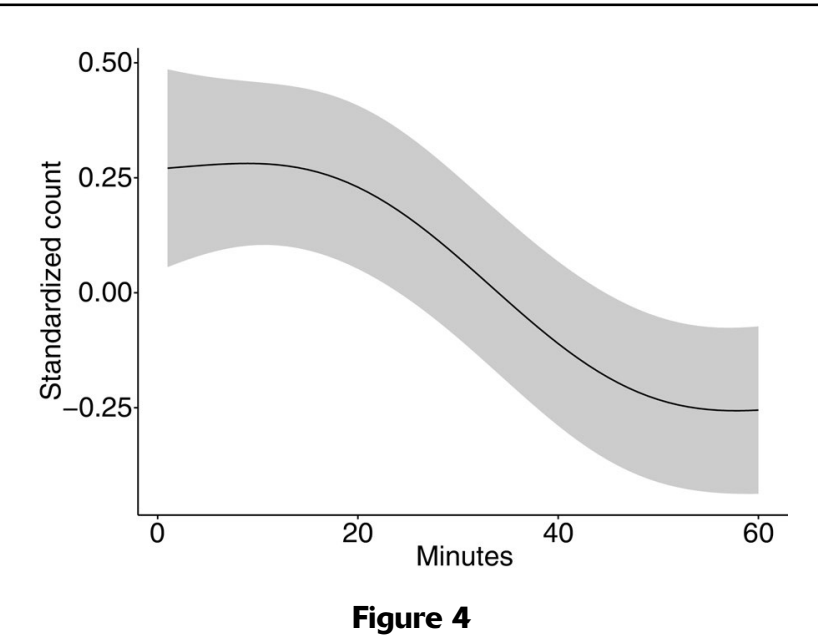

Changes in fish abundance during the acclimation period (first $60 \mathrm{~min}$ ) following deployment of Modular Optical Underwater Sampling System platforms at selected reef sites in the Florida Middle Grounds. The gray shaded area represents the $95 \%$ confidence interval. Trends indicate a decrease in abundance with an asymptotic response occurring at around $45 \mathrm{~min}$. The experiment was conducted during August 2014 and July and August 2015.

forage and interact with the habitat and each other at around 30 min after deployment.

Results from vehicle interaction GAMs indicate that significant terms and overall fit of the models differed between behavioral guilds and between vehicles within each guild (Table 2). From a qualitative perspective, the pelagic pursuers group had strong attraction to all of the vehicles tested and was the most obvious group to characterize (Fig. 5). The model for the AUV had significant effects for RVA, vehicle range, and transect number, but habitat complexity was not significant. The AUV model explained $48.9 \%$ of the deviance with an $r^{2}$ of 0.43 . The TV model had significant effects for vehicle range, transect number, and habitat complexity, but RVA was not significant. The TV model explained 59.3\% of the deviance with an $r^{2}$ of 0.29 . The ROV model showed significant effects for vehicle range, but vehicle altitude, transect number, and habitat complexity were not significant. The ROV model explained $81 \%$ of the deviance with an $r^{2}$ of 0.46 . Pelagic pursuers had spikes in abundance when vehicles were close in proximity to the MOUSS platforms ( $50 \mathrm{~m}$ ) (Fig. 5). Passage of the slower-moving AUV and ROV resulted in a spike in relative fish abundance at closer ranges $(\sim 10 \mathrm{~m})$ than passage of the fast-moving TV $(\sim 50 \mathrm{~m})$. Relative abundance of pelagic pursuers increased with increasing AUV altitude but had no relationship to TV altitude. The effect of relative altitude could not be tested on the ROV because all passes were within the low category. Increasing the number of transects generally resulted in peak increases in relative abundance between the third and fourth transect for the AUV and TV, but this pattern was not evident for the ROV. 


\section{Table 2}

Generalized additive model run results by behavioral guild and survey vehicle, used to assess changes in the relative abundance of fish due to vehicle passage at sites in the Florida Middle Grounds during August 2014 and July and August 2015. Vehicles evaluated included an autonomous underwater vehicle (AUV), a towed vehicle (TV), and a remotely operated vehicle (ROV). $P$-values are provided for each variable included in the models: relative vehicle altitude above the seafloor (RVA), transect number, habitat complexity, and vehicle range. Also given are the sample size $(n)$, percentage of deviance explained, and coefficient of determination $\left(r^{2}\right)$. Asterisks $(*)$ indicate significant variables $(P<0.05)$. NA indicates a variable that was not used in a particular model run.

\begin{tabular}{ccccccccc}
\hline Guild & Vehicle & $n$ & Intercept & RVA & $\begin{array}{c}\text { Transect } \\
\text { number }\end{array}$ & $\begin{array}{c}\text { Habitat } \\
\text { complexity }\end{array}$ & $\begin{array}{c}\text { Vehicle } \\
\text { range }(\mathrm{m})\end{array}$ & $\begin{array}{c}\text { Deviance } \\
\text { explained }\end{array}$ \\
$r^{2}$
\end{tabular}

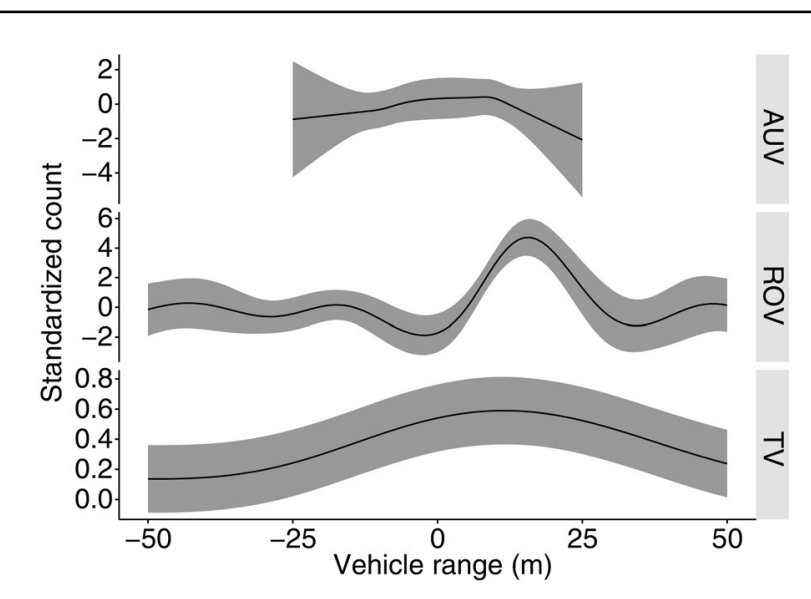

Figure 5

Change in standardized fish counts observed at selected reef sites in the Florida Middle Grounds for the pelagic pursuers guild as a function of vehicle range (meters) and by vehicle type. Survey vehicles used in this experiment included an autonomous underwater vehicle (AUV), a remotely operated vehicle (ROV), and a towed vehicle (TV). Predictions were made by using the GAM predict function in the $R$ package mgcv, and parameters were set in the models as follows: first transect transited, the relative vehicle altitude from the seafloor was set at the middle level $(2 \mathrm{~m})$, and habitat complexity was set at the average qualitative rating (2.5). The gray shaded areas represent the $95 \%$ confidence intervals. Surveys were conducted during August 2014 and July and August 2015.
From a qualitative perspective, the benthic pursuers group exhibited strong attraction to all of the vehicles tested but in general were not fast enough to keep up with a transiting vehicle. Therefore, members of this guild tended to only briefly chase vehicles following passage (Fig. 6). For the benthic pursuers guild, results from the AUV model indicate significant effects for RVA and habitat complexity, but vehicle range was marginally significant and transect number was not significant. The AUV model explained $46.7 \%$ of the deviance with an $r^{2}$ of 0.52 (Table 2). The TV model had significant effects for RVA, vehicle range, transect number, and habitat complexity. The TV model explained $34.0 \%$ of the deviance with an $r^{2}$ of 0.22 . The ROV model had significant effects for RVA, vehicle range, transect number, and habitat complexity. The ROV model explained $13.9 \%$ of the deviance with an $r^{2}$ of 0.10 . For the benthic pursuers guild, relative abundance increased with decreasing vehicle range to the MOUSS sampling volume, peaking at a distance of around $0 \mathrm{~m}$ and remaining at elevated levels following vehicle passage (Fig. 6). In general, relative abundance of this group also increased as a function of transect number with varying results relative to vehicle type. For both slow-transiting vehicles (AUV and ROV), increasing RVA resulted in increased relative abundance; whereas, with the TV relative abundance decreased with increasing RVA.

From a qualitative perspective, the lateral movers group tended to flee laterally as the vehicle neared the MOUSS platform sampling volume (Fig. 7). For the lateral movers guild, results from the TV model indicate significant 


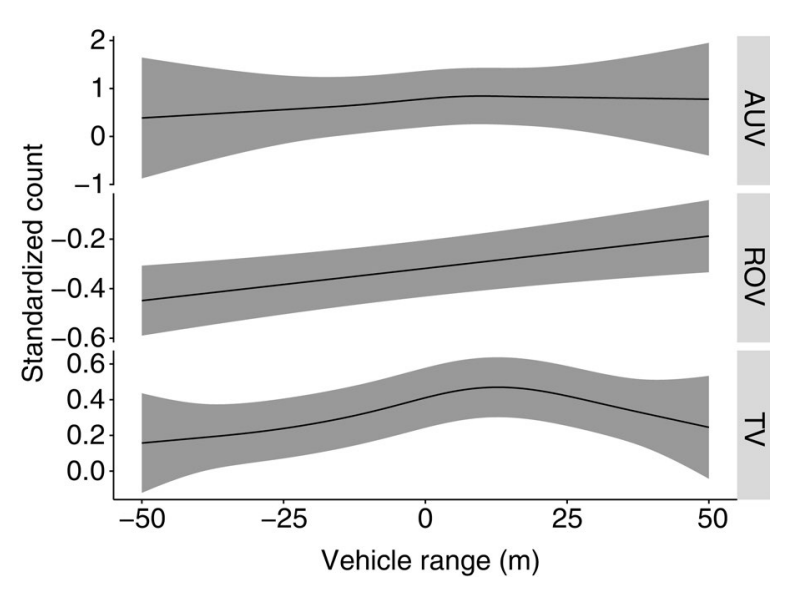

Figure 6

Change in standardized fish counts observed at selected reef sites in the Florida Middle Grounds of the benthic pursuers guild as a function of vehicle range (meters) and by vehicle type. Survey vehicles used in this experiment were an autonomous underwater vehicle (AUV), a remotely operated vehicle (ROV), and a towed vehicle (TV). Predictions were made by using the GAM predict function in the $\mathrm{R}$ package mgcv, and parameters were set in the models as follows: first transect transited, the relative vehicle altitude from the seafloor was set at the middle level $(2 \mathrm{~m})$, and habitat complexity was set at the average qualitative rating (2.5). The gray shaded areas represent the $95 \%$ confidence intervals. Surveys were conducted during August 2014 and July and August 2015.

effects on relative abundance for RVA, transect number, and habitat complexity, but vehicle range was not significant. The TV model explained $26.8 \%$ of the deviance with an $r^{2}$ of 0.73 (Table 2). Results from the ROV model indicate significant effects on relative abundance for RVA, transect number, habitat complexity, and vehicle range. The ROV model explained $38.3 \%$ of the deviance with an $r^{2}$ of 0.14 . There were not enough interactions with the AUV to analyze effects for the lateral movers guild. Lateral movers guild fish abundance decreased significantly with decreasing vehicle range to the MOUSS platform sampling volume (Fig. 7). Following passage of the TV, fish tended to return to the MOUSS platform sampling volume; whereas, they did not return following ROV passage. Relative abundance of the lateral movers guild decreased with increasing number of transects surveyed with the ROV. Relative vehicle altitude above the seafloor had opposite effects by vehicle, with low transect numbers for the TV resulting in increased relative abundance and with increased transect number for the ROV resulting in increased relative abundance. This result might be due to the differences in habitat preferences between vermilion snapper (semi-pelagic) and porgies (benthic) having been mixed into the same model.

From a qualitative perspective, the down movers guild exhibited negative reactions to the vehicles, and fish in this

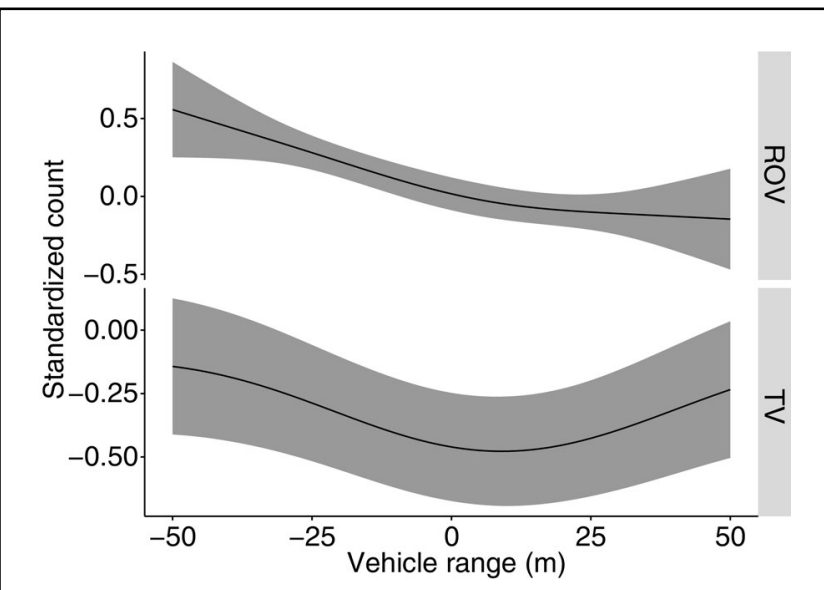

Figure 7

Change in standardized fish counts observed at selected reef sites in the Florida Middle Grounds of the lateral movers guild as a function of vehicle range (meters) and by vehicle type. Survey vehicles used in this experiment were a remotely operated vehicle (ROV) and a towed vehicle (TV). Predictions were made by using the GAM predict function in the $\mathrm{R}$ package mgcv, and parameters were set in the models as follows: first transect transited, the relative vehicle altitude from the seafloor was set at the middle level $(2 \mathrm{~m})$, and habitat complexity was set at the average qualitative rating (2.5). The gray shaded areas represent the $95 \%$ confidence intervals. Surveys were conducted during August 2014 and July and August 2015.

group fled down into available interstitial spaces in the local habitat but did not leave the MOUSS platform sampling volume (Fig. 8). Relative abundance of the down movers guild decreased with decreasing vehicle range, and the steepness of the decline and subsequent increase appears to be dependent on vehicle type. For the down movers guild, results from the AUV model indicate significant effects on relative abundance for RVA, transect number, and habitat complexity, but range was not significant. The AUV model explained $98.0 \%$ of the deviance with an $r^{2}$ of 0.98 (Table 2). Results from the TV model indicate significant effects on down movers guild relative abundance for RVA, transect number, habitat complexity, and vehicle range. The TV model explained $60.8 \%$ of the deviance with an $r^{2}$ of 0.38 . Results from the ROV model indicate significant effects on relative abundance for RVA, transect number, habitat complexity, and vehicle range. The ROV model explained $18.6 \%$ of the deviance with an $r^{2}$ of 0.14 . Strongest responses were observed for the TV and ROV (fastest vehicles), and the weakest responses were observed for the AUV (slowest vehicle). For both the AUV and ROV, down movers guild relative abundance decreased with increasing transect number. In contrast, results from the TV model indicate that relative abundance increased through the first 5 transects followed by decreasing relative abundance thereafter. Increasing RVA indicates increasing down movers guild 


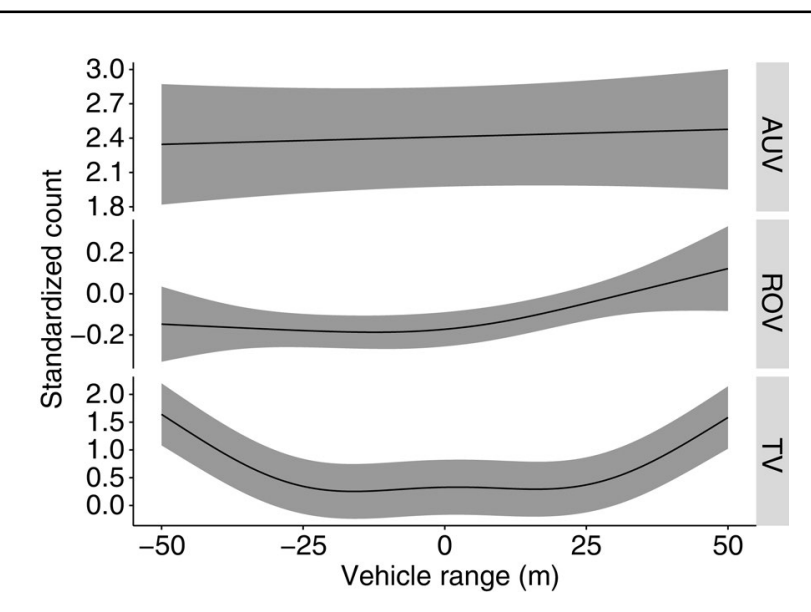

Figure 8

Change in standardized fish counts observed at selected reef sites in the Florida Middle Grounds of the down movers guild as a function of vehicle range (meters) and by vehicle type. Survey vehicles used in this experiment were an autonomous underwater vehicle (AUV), a remotely operated vehicle (ROV), and a towed vehicle (TV). Predictions were made by using the GAM predict function in the $\mathrm{R}$ package mgcv, and parameters were set in the models as follows: first transect transited, the relative vehicle altitude from the seafloor was set at the middle level $(2 \mathrm{~m})$, and habitat complexity was set at the average qualitative rating (2.5). The gray shaded areas represent the $95 \%$ confidence intervals. Surveys were conducted during August 2014 and July and August 2015.

relative abundance for the AUV and ROV but indicates a decreasing trend in relative abundance for the TV.

From a qualitative perspective, relative abundance of the local reactive guild tended to change little in relation to vehicle passage (Fig. 9). However, observations on camera indicate that individuals of this group tended to increase activity with a vehicle present but did not flee the sampling volume in front of the MOUSS platforms (i.e., locally reactive). For the local reactive guild, results from the TV model indicate significant effects on relative abundance for RVA, transect number, habitat complexity, and vehicle range. The TV model explained $11.6 \%$ of the deviance with an $r^{2}$ of 0.17 (Table 2). Results from the ROV model indicate significant effects on relative abundance for RVA, transect number, habitat complexity, and vehicle range. The ROV model explained $29.7 \%$ of the deviance with an $r^{2}$ of 0.42 . The AUV had too small of a sample size to evaluate this group. Vehicle altitude could only be evaluated for the TV and was negatively related to relative abundance.

\section{Discussion}

Species-specific gear interactions were difficult to capture; however, various patterns of fish response to the vehicles allowed classification of species into behavioral guilds.

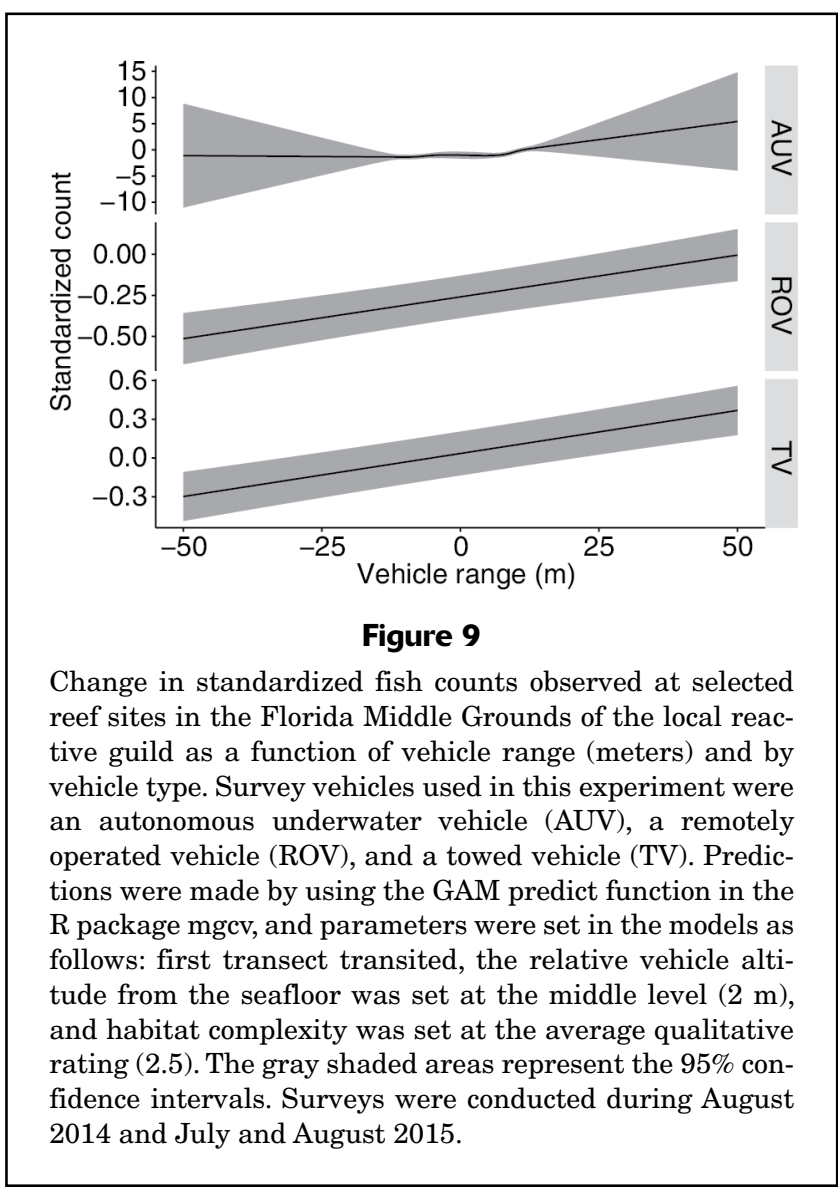

The use of GAMs proved to be an effective method to examine changes in relative abundance of fish as a function of vehicle range and relative altitude, transect number, and habitat complexity. The effect of each variable is dependent on the behavioral guild of interest, but vehicle range was a consistent predictor of relative changes in abundance regardless of vehicle and behavioral guild. In general, the best fitting models were associated with the strongest behavioral responses, such as the attraction behavior observed for the pelagic pursuers guild and the avoidance behavior observed for the down movers guild. Finally, although logistically difficult to conduct, the testbed method we used to evaluate fish responses to sampling gear was effective and potentially will provide a path forward to conducting gear calibrations in the future.

The consistency of vehicle range in the GAMs allowed the development of functional relationships between vehicle range and the change in relative abundance in the MOUSS platform sampling volume (Figs. 4-9). Although many studies have recognized or coarsely evaluated fish responses to sampling vehicles (Ralston et al., 1986; Richards, 1986; Koslow et al., 1995; Trenkel et al., 2004a, 2004b; Lorance and Trenkel, 2006; Ryer et al., 2009), no studies have included estimation of a functional relationship that predicts relative change in abundance to an approaching vehicle (i.e., far-field response). The testbed approach proved to be a robust method of deriving 
attraction and avoidance functions that in future iterations of this research will be useful for conducting vehicle calibration studies and for modifying fish abundance and density estimates.

The benthic and pelagic pursuers guilds had strong attraction to the survey vehicles. Both guilds included several managed species that are important components of fisheries that operate in the GOM, including scamp, red grouper (Epinephelus morio), and greater amberjack. In addition to the obvious distinction of habitat preference, these guilds had distinct differences in ability to match vehicle speed while in pursuit. Pelagic pursuers concentrated behind vehicles and could easily maintain pace with them; however, their response was not persistent over repeated transects (Fig. 5). The strong attraction signal, coupled with the pelagic pursuers ability to match vehicle speed, indicates that the same fish could be observed with vehicles along the transect line, resulting in overestimation of fish abundance or density. Unfortunately, given the relatively short transect length in our surveys, we could not determine the distance over which pelagic pursuers continued to follow a vehicle.

Conversely, benthic pursuers gave short chase following vehicle passage and could not keep up with vehicles; however, they repeated the behavior in subsequent vehicle transects (Fig. 6). This finding indicates that new individuals from the benthic pursuers group are likely being observed with the vehicles down the transect line. Thus, density estimates for species of this guild likely will not require adjustment because the observed fish did not aggregate around the vehicles and, as a result, were not drawn down a transect line. Of higher concern for observing benthic pursuers guild fish like groupers is their coloration and mottling patterns (Burge et al., 2012; Watson et al., 2014) and their tendency to hide underneath structure, both of which makes them difficult to observe (Camp et al., 2013). Therefore, understanding detection probability and sighting functions may be more critical for estimating abundance or density for species in the benthic pursuers guild. In our experiment, the following behavior seems to be most strongly associated with piscivorous fish, perhaps as a stalking or investigatory type of behavior. Strong attraction to ROVs has also been observed for yellowtail rockfish (Sebastes flavidus) (Stoner et al., 2008) and Pacific hake (Merluccius productus) (Adams et al., 1995); however, neither study quantified the response. In general, attraction responses need to be well understood because they concentrate fish, could result in overestimation of density, and are thus not conservative.

Gear avoidance is one of the more common behaviors noted in studies (Adams et al., 1995; Koslow et al., 1995; Uiblein et al., 2003; Lorance and Trenkel, 2006) and was most clearly observed for the lateral and down movers guilds. Lateral movers guild fish, which include snapper and grunts, exhibited significant decreases in abundance with decreasing vehicle range, indicating a flight response to approaching vehicles. Avoidance behaviors have been linked to the looming effect in which fast, direct approaches increase the likelihood and strength of the flight response
(Frid and Dill, 2002). An analysis of fine-scale data collected from frame-by-frame analysis of a subset of the UHSI videos revealed that vermilion snapper scaled their response from slow-swimming behavior and loosely aggregated schools when the vehicle was distant to tightly aggregated schools and fast-swimming behavior when the TV came into the sampling volume (Somerton et al., 2017). Both the ROV and TV displaced lateral movers guild fish from the MOUSS platform sampling volume prior to the vehicle's arrival; however, there was not enough AUV data to analyze. The persistence of the flight response was vehicle dependent; for instance, abundance quickly returned to pre-disturbance levels following TV transit; whereas, abundance remained depressed following ROV transit. The difference in the persistence of the effect could be related to the extended length of time the ROV tether remained in the vicinity of the MOUSS platform. Calibration experiments will be necessary for vehicle-based surveys that target fish species in this guild and that exhibit strong flight response as there is high likelihood that abundance and density will be underestimated.

Another clear case of vehicle avoidance was associated with the down movers guild. The flight response to the approaching vehicle was consistent and strongly oriented downward into protective habitat, but fish did not depart the sampling volume (i.e., present but no longer detected). Most of the species in the down movers guild in this analysis are in the family Pomacentridae (e.g., Chromis spp.), are generally small in body size, and are found in close proximity to reef habitat. The distinct downward response to the vehicle was also observed when predators, such as great barracuda swam through the sampling volume, and thus we presume this behavior to be related to predator avoidance and response to novel threats. It could be that the body size of the species in this group precludes them from outswimming a predator in open water and that a strategy to stay near protective habitat into which they can flee is advantageous. In addition, the response appears to be weakest in relation to the AUV and strongest for the TV and ROV. As with the response of the lateral movers, the looming effect is strongly associated with the speed of the vehicle (Frid and Dill, 2002) and might explain the observed differences in fish responses between vehicles. The AUV travels slower and at higher altitudes than the other vehicles and therefore has a decreased looming effect, which perhaps tempers the flight response into protective habitat (i.e., perceived threat is dampened). As with the lateral movers guild, gear calibrations are required for species in this group to compensate for changes in abundance due to the flight response.

The local reactive guild is composed largely of species of ornamental reef fish, such as butterflyfish (Chaetodon spp.), filefish (Monacanthus spp.), and damselfish (Stegastes spp.). For this guild, abundance increased as a function of vehicle range, and fish of this guild exhibited little attraction or avoidance to the vehicles and, as with fish of the down movers guild, did not leave the sampling volume. Review of video also revealed increased activity (i.e., reactive behavior) following vehicle passage. Further, 
abundance increased with increasing number of transects. Because fish of the local reactive guild were not attracted to the vehicles but abundance increased as a function of vehicle range and over transects, vehicle passage could have altered the behavior of the fish, causing a coincident increase in detectability by the MOUSS platforms. In other words, detection rather than abundance is potentially changing, at least from the perspective of the MOUSS cameras.

Detection probability and sighting functions (i.e., range to positive identification of fish) have been shown to be critical for estimation of fish densities for strip-transect and distance sampling methods (Sale and Sharp, 1983; Ensign et al., 1995; Cheal and Thompson, 1997), even for species that have minimal or no avoidance behaviors (Kulbicki and Sarramégna, 1999). Although the functions developed in this work add critical information about how relative fish abundance changed prior to vehicle arrival, vehicle-specific sighting functions are equally important to develop even for species exhibiting minimal or no behavioral response. Further, it is important to understand that the MOUSS platforms in our experiment have their own detection probability and sighting functions; therefore, what is presented here is relative to the MOUSS platform observations. Thus, our modeling does not necessarily lead to unbiased estimates of abundance or biomass. Further research that could establish fish density in a known area, and therefore establish the standard in which the optical systems were deployed, would be a useful but extremely difficult undertaking. Finally, all of the key components necessary to estimate fish density will likely have important covariates to consider, variables such as light, water clarity, and habitat complexity. Light and water clarity were fairly constant over the course of the experiment; however, habitat complexity varied among sites. Both of these findings may or may not occur in basin-wide surveys but are critical considerations for those types of surveys (e.g., in the Gulf of Mexico).

Although we were able to estimate functions that were based on vehicle range and that included important covariates to help evaluate fish response (e.g., habitat complexity), we were unable to connect those responses to any specific vehicle stimuli (e.g., noise or light). Sensory mechanisms of fish that detect the sound, light, and motion of a vehicle are all critical components that likely incite fish reaction and potentially bias observations in undetermined directions and magnitude. For instance, in an experiment designed to observe soniferous fish behavior, ROV noise induced a strong negative behavioral response that affected observations during sampling (Rountree and Juanes, 2010). Similarly, responses to artificial lighting range from attraction to avoidance and are species specific (McIninch and Hocutt, 1987; Marchesan et al., 2005; Raymond and Widder, 2007). Furthermore, the order of stimuli detection and their associated thresholds in fish are uncertain. For instance, the sound produced by motors and propellers or the vibration of tow cables generate noise that could stimulate the lateral movers guild fish and cause a response prior to the fish detecting vehicle lights. Similarly, positioning beacons generate sound but generally operate at higher frequencies than fish can detect (Mann et al., 2001; Popper, 2003; Stoner et al., 2008).

Ultimately, noise-inducing equipment, such as tethers, tow cables, and propellers are critical components of vehicles; therefore, experiments should include a capacity to measure relevant stimuli in order to relate them to fish response. For instance, future iterations of this type of experiment and large-scale ocean observation systems (Rountree et al., 2020) would benefit from having a suite of acoustic sensors and light meters to identify specific vehicle noise and light production signatures. Light meters and turbidity sensors for detecting ambient conditions in the environment would also be useful for estimation of vehicle- and condition-specific sighting functions. Finally, experimental methods that place sampling platforms at specific locations and on specific habitat would likely result in more interactions with target species and enable development of species-specific range functions. Cameras that have increased FOV (e.g., $360^{\circ}$ or full spherical) might be useful, given that it has been reported that they increase fish detection (Kilfoil et al., 2017; Campbell et al., 2018). Additionally, full-spherical cameras would be useful in vehicle detection when they transit behind or above the intended transect line, and thus more gear interactions could be captured.

The original statistical analysis was envisioned to create single-species models that include vehicle type as a variable in order to facilitate direct comparisons of vehicle performance. Logistics of the ship, however, caused us to stage the experiment in 2 separate periods. Therefore, in the experiment, each vehicle was tested in somewhat different habitats that had varied fish assemblages and densities, making it impossible to expose each vehicle to a standardized set of conditions. Because of the difficulty of sampling different sites, we created the habitat complexity variable in an effort to standardize site conditions and clarify changes in abundance that were associated with vehicle passage. Additionally, species-specific interactions in the coincident sampling volume in space and time were rare, thus making single-species models problematic to estimate. Other at-sea conditions also created situations where the AUV in particular was not deployed as frequently as the other vehicles and therefore had fewer interactions with target species. For these reasons, we felt that a direct comparison that used a singular model (i.e., inclusion of a vehicle variable) was not defensible. Importantly, our observations were that each vehicle had good and bad traits for sampling different habitats and had differential utility depending on target species. Thus, we made an effort to not compare vehicles qualitatively (i.e., good or bad). We envision that the outcomes of our work potentially would help researchers select a vehicle that best fits the target environment and species they intend to sample.

Critically, underlying fish density could not be controlled; therefore, statistical analysis, model estimation, and resultant explanatory capacity were shaped around the data that we were able to obtain. Recent efforts to 
estimate species-specific absolute abundance, such as the Great Red Snapper Count (Stunz et al. ${ }^{2}$ ), rely on integration of data across a wide spectrum of instrumentation. Basin-scale efforts such as this require some form of calibration treatment obtained over a wide range of sampling conditions and habitats (e.g., water clarity and low to high relief) and across a variety of platforms and instruments capable of scaling to common units (e.g., fish density per unit area or volume). To achieve proper calibration, efforts such as those laid out in this paper will be necessary and will undoubtedly be very expensive in time, complexity, and expense. Without proper methods to calibrate instruments against known densities, efforts such as those undertaken in this experiment, while interesting, might not result in desired outcomes. Thus targets such as absolute abundance will remain elusive or will be heavily reliant on poorly understood assumptions about vehicle sampling properties and their associated biases.

\section{Conclusions}

The test-bed experiment was logistically difficult to conduct because many moving pieces had to be synchronized to produce coincident sampling volumes and useful data. Logistical difficulties included temporal synchronization of all sampling equipment, orientation of the MOUSS platforms perpendicular to the transect line transited by the vehicles, geolocation of cameras once deployed, and navigation of vehicles precisely down transect lines. Although the logistics of the experiment went smoothly and improved over time, it was equally difficult to detect interactions for specific fish species. Another issue is that manual annotation of videos is a slow process, and producing data sets therefore is a time intensive process that would be enhanced with automated approaches, particularly those that can be used to generate data on small spatio-temporal scales (Shafait et al., 2017). A field experiment that would encompass all of the potential variables of interest (e.g., species movement patterns, water conditions, and vehicle effects) would be difficult to coordinate and control; therefore, a logical next step is to evaluate the question in a simulation-modeling framework (Kim and Wardle, 1998).

\section{Acknowledgments}

The authors would like to acknowledge the NMFS Office of Science and Technology for continued support throughout this 5-year strategic initiative. We would like to thank the Mississippi Laboratories of the NMFS Southeast

\footnotetext{
${ }^{2}$ Stunz, G. W., W. F. Patterson III, S. P. Powers, J. H. Cowan Jr., J. R. Rooker, R. A. Ahrens, K. Boswell, L. Carleton, M. Catalano, J. M. Drymon et al. 2021. The great red snapper count: estimating the absolute abundance of age-2+ red snapper (Lutjanus campechanus) in the U.S. Gulf of Mexico, 152 p. Mississippi-Alabama Sea Grant Consort., Ocean Springs, MS. [Available from website.]
}

Fisheries Science Center, the University of South Florida, and the Florida Institute of Oceanography for providing personnel and dockside support to stage and conduct this complicated experiment. We would also like to thank the crews of RV Pelican (LUMCON, Cocodrie, LA) and RV Weatherbird II (FIO, St. Petersburg, FL).

\section{Literature cited}

Adams, P. B., J. L. Butler, C. H. Baxter, T. E. Laidig, K. A. Dahlin, and W. W. Wakefield.

1995. Population estimates of Pacific coast groundfishes from video transects and swept-area trawls. Fish. Bull. 93:446-455.

Afanasyev, P. K., A. M. Orlov, and R. N. Novikov.

2014. Comparative characteristic of sablefish Anoplopoma fimbria in catches with passive and active fishing gear in the northwestern Pacific Ocean. J. Ichthyol. 54:146-164. Crossref

Amin, R., B. L. Richards, W. Misa, J. Taylor, G. C. Young, D. Miller, A. Rollo, C. Demarke, H. Singh, J. Childress et al.

2017. The Modular Optical Underwater Survey System (MOUSS) for in situ sampling of fish assemblages. In OCEANS 2017-Anchorage; Anchorage, 18-21 September, p. 1-8. Inst. Electr. Electr. Eng., Piscataway, NJ. [Available from website.]

Armstrong, R. A., and H. Singh.

2012. Mesophotic coral reefs of the Puerto Rico shelf. In Seafloor geomorphology as benthic habitat: GeoHab atlas of seafloor geomorphic features and benthic habitats (P. T. Harris and E. K. Baker, eds.), p. 365-374. Elsevier, London.

Austin, H. M., and J. I. Jones.

1974. Seasonal variation of physical oceanographic parameters on the Florida Middle Ground and their relation to zooplankton biomass on the West Florida Shelf. Fla. Sci. $37: 16-32$.

Bacheler, N. M., and K. W. Shertzer.

2015. Estimating relative abundance and species richness from video surveys of reef fishes. Fish. Bull. 113:15-26. Crossref

Burge, E. J., J. D. Atack, C. Andrews, B. M. Binder, Z. D. Hart, A. C. Wood, L. E. Bohrer, and K. Jagannathan.

2012. Underwater video monitoring of groupers and the associated hard-bottom reef fish assemblage of North Carolina. Bull. Mar. Sci. 88:15-38. Crossref

Camp, E. F., K. E. Lohr, S. C. Barry, P. G. Bush, C. A. Jacoby, and C. Manfrino.

2013. Microhabitat associations of late juvenile Nassau grouper (Epinephelus striatus) off Little Cayman, BWI. Bull. Mar. Sci. 89:571-581. Crossref

Campbell, M. D., J. Salisbury, R. Caillouet, W. B. Driggers, and J. Kilfoil.

2018. Camera field-of-view and fish abundance estimation: a comparison of individual-based model output and empirical data. J. Exp. Mar. Biol. Ecol. 501:46-53. Crossref

Cheal, A. J., and A. A. Thompson.

1997. Comparing visual counts of coral reef fish: implications of transect width and species selection. Mar. Ecol. Prog. Ser. 158:241-248. Crossref

Clarke, M. E., N. Tolimieri, and H. Singh.

2009. Using the Seabed AUV to assess populations of groundfish in untrawlable areas. In The future of fisheries science in North America (R. J. Beamish and B. J. Rothschild, eds.), p. 357-372. Springer, Dordrecht, Netherlands. 
Darcy, G. H., and E. J. Gutherz.

1984. Abundance and density of demersal fishes on the West Florida Shelf, January 1978. Bull. Mar. Sci. 34:81-105.

Emslie, M. J., A. J. Cheal, M. A. MacNeil, I. R. Miller, and H. P. A. Sweatman.

2018. Reef fish communities are spooked by scuba surveys and may take hours to recover. PeerJ 6:e4886. Crossref

Ensign, W. E., P. L. Angermeier, and C. A. Dolloff.

1995. Use of line transect methods to estimate abundance of benthic stream fishes. Can. J. Fish. Aquat. Sci. 52:213-222. Crossref

Frid, A., and L. Dill.

2002. Human-caused disturbance stimuli as a form of predation risk. Conserv. Ecol. 6(1):11. Crossref

Grasty, S. E.

2014. Use of a towed camera system for estimating reef fish populations densities on the West Florida Shelf. M.S. thesis, 89 p. Univ. South Fla., St. Petersburg, FL. [Available from website.]

Gray, A. E., I. D. Williams, K. A. Stamoulis, R. C. Boland,

K. C. Lino, B. B. Hauk, J. C. Leonard, J. J. Rooney, J. M. Asher,

K. H. Lopes Jr. et al.

2016. Comparison of reef fish survey data gathered by open and closed circuit SCUBA divers reveals differences in areas with higher fishing pressure. PLoS ONE 11(12):e0167724. Crossref

Hall-Spencer, J., V. Allain, and J. H. Fosså.

2002. Trawling damage to Northeast Atlantic ancient coral reefs. Proc. R. Soc. Lond., B 269:507-511. Crossref

Jagielo, T., A. Hoffmann, J. Tagart, and M. Zimmermann.

2003. Demersal groundfish densities in trawlable and untrawlable habitats off Washington: implications for the estimation of habitat bias in trawl surveys. Fish. Bull. 101:545-565.

Kilfoil, J., M. Bond, M. D. Campbell, J. Kiszka, K. Gastrich, M. Heithaus, Y. Zhang, and A. Wirsing.

2017. Baited Remote Underwater Video surveys undercount sharks at high densities: insights from full-spherical camera technologies. Mar. Ecol. Prog. Ser. 585:113-121. Crossref

Kim, Y.-H., and C. S. Wardle.

1998. Modelling the visual stimulus of towed fishing gear. Fish. Res. 34:165-177. Crossref

Koenig, C. C., F. C. Coleman, C. B. Grimes, G. R. Fitzhugh,

K. M. Scanlon, C. T. Gledhill, and M. Grace.

2000. Protection of fish spawning habitat for the conservation of warm-temperate reef-fish fisheries of shelf-edge reefs of Florida. Bull. Mar. Sci. 66:593-616.

Koslow, J. A., R. Kloser, and C. A. Stanley.

1995. Avoidance of a camera system by a deepwater fish, the orange roughy (Hoplostethus atlanticus). Deep-Sea Res., I 42:233-244. Crossref

Kulbicki, M., and S. Sarramégna.

1999. Comparison of density estimates derived from strip transect and distance sampling for underwater visual censuses: a case study of Chaetodontidae and Pomacanthidae. Aquat. Living Resour. 12:315-325. Crossref

Lembke, C., S. Grasty, A. Silverman, H. Broadbent, S. Butcher, and S. Murawski.

2017. The Camera-Based Assessment Survey System (C-BASS): a towed camera platform for reef fish abundance surveys and benthic habitat characterization in the Gulf of Mexico. Cont. Shelf Res. 151:62-71. Crossref

Lorance, P., and V. M. Trenkel.

2006. Variability in natural behaviour, and observed reactions to an ROV, by mid-slope fish species. J. Exp. Mar. Biol. Ecol. 332:106-119. Crossref
Mangi, S. C., and C. M. Roberts.

2006. Quantifying the environmental impacts of artisanal fishing gear on Kenya's coral reef ecosystems. Mar. Pollut. Bull. 52:1646-1660. Crossref

Mann, D. A., D. M. Higgs, W. N. Tavolga, M. J. Souza, and A. N. Popper.

2001. Ultrasound detection by clupeiform fishes. J. Acoust. Soc. Am. 109:3048-3054. Crossref

Marchesan, M., M. Spoto, L. Verginella, and E. A. Ferrero. 2005. Behavioural effects of artificial light on fish species of commercial interest. Fish. Res. 73:171-185. Crossref

McIninch, S. P., and C. H. Hocutt.

1987. Effects of turbidity on estuarine fish response to strobe lights. J. Appl. Ichthyol. 3:97-105. Crossref

O'Connell, V. M., and D. W. Carlile.

1993. Habitat-specific density of adult yelloweye rockfish (Sebastes ruberrimus) in the eastern Gulf of Alaska. Fish. Bull. 91:304-309.

Olla, B. L., M. W. Davis, and C. H. Ryer.

1998. Understanding how the hatchery environment represses or promotes the development of behavioral survival skills. Bull. Mar. Sci. 62:531-550.

Parker, D., H. Winker, A. T. F. Bernard, E. R. Heyns-Veale,

T. J. Langlois, E. S. Harvey, and A. Götz.

2016. Insights from baited video sampling of temperate reef fishes: how biased are angling surveys? Fish. Res. 179:191-201. Crossref

Patterson, W. F., III, M. A. Dance, and D. T. Addis.

2009. Development of a remotely operated vehicle based methodology to estimate fish community structure at artificial reef sites in the northern Gulf of Mexico. Proc. Gulf Caribb. Fish. Inst. 61:263-270.

Pierce, D. J., and B. Mahmoudi.

2001. Nearshore fish assemblages along the central west coast of Florida. Bull. Mar. Sci. 68:243-270.

Popper, A. N.

2003. Effects of anthropogenic sounds on fishes. Fisheries 28(10):24-31. Crossref

$\mathrm{R}$ Core Team.

2020. R: a language and environment for statistical computing. R Foundation for Statistical Computing, Vienna, Austria. [Available from website, accessed January 2021.]

Ralston, S., R. M. Gooding, and G. M. Ludwig.

1986. An ecological survey and comparison of bottom fish resource assessments (submersible versus handline fishing) at Johnston Atoll. Fish. Bull. 84:141-155.

Raymond, E. H., and E. A. Widder.

2007. Behavioral responses of two deep-sea fish species to red, far-red, and white light. Mar. Ecol. Prog. Ser. 350:291-298. Crossref

Rezak, R., T. J. Bright, and D. W. McGrail.

1985. Reefs and banks of the northwestern Gulf of Mexico: their geological, biological, and physical dynamics, $259 \mathrm{p}$. Wiley, New York.

Richards, L. J.

1986. Depth and habitat distributions of three species of rockfish (Sebastes) in British Columbia: observations from the submersible PISCES IV. Environ. Biol. Fish. 17:13-21. Crossref

Roberts, J. M., A. J. Wheeler, and A. Freiwald.

2006. Reefs of the deep: the biology and geology of cold-water coral ecosystems. Science 312:543-547. Crossref

Rountree, R. A., and F. Juanes.

2010. First attempt to use a remotely operated vehicle to observe soniferous fish behavior in the Gulf of Maine, Western Atlantic Ocean. Curr. Zool. 56:90-99. Crossref 
Rountree, R. A., J. Aguzzi, S. Marini, E. Fanelli, F. C. De Leo, J. Del Rio, and F. Juanes.

2020. Towards an optimal design for ecosystem-level ocean observatories. In Oceanography and marine biology: an annual review, vol. 58 (S. J. Hawkins, A. L. Allcock, A. E. Bates, A. J. Evans, L. B. Firth, C. D. McQuaid, B. D. Russell, I. P. Smith, S. E. Swearer, and P. A. Todd, eds.), p. 79-106. Taylor and Francis Group, Boca Raton, FL.

Royle, J. A., J. D. Nichols, K. U. Karanth, and A. M. Gopalaswamy. 2009. A hierarchical model for estimating density in cameratrap studies. J. Appl. Ecol. 46:118-127. Crossref

Ryer, C. H., A. W. Stoner, P. J. Iseri, and M. L. Spencer. 2009. Effects of simulated underwater vehicles lighting on fish behavior. Mar. Ecol. Prog. Ser. 391:97-106. Crossref

Sale, P. F., and B. J. Sharp.

1983. Correction for bias in visual transect censuses of coral reef fishes. Coral Reefs 2:37-42. Crossref

Shafait, F., E. S. Harvey, M. R. Shortis, A. Mian, M. Ravanbakhsh,

J. W. Seager, P. F. Culverhouse, D. E. Cline, and D. R. Edgington. 2017. Towards automating underwater measurement of fish length: a comparison of semi-automatic and manual stereo-video measurements. ICES J. Mar. Sci. 74:1690-1701. Crossref

Singh, H., A. Can, R. Eustice, S. Lerner, N. McPhee, and C. Roman. 2004. Seabed AUV offers new platform for high-resolution imaging. EOS Trans. Am. Geophys. Union 85:289-296. Crossref

Somerton, D. A., K. Williams, and M. D. Campbell.

2017. Quantifying the behavior of fish in response to a moving camera vehicle by using benthic stereo cameras and target tracking. Fish. Bull. 115:343-354. Crossref

Stierhoff, K. L., J. L. Butler, S. A. Mau, and D. W. Murfin.

2013. Abundance and biomass estimates of demersal fishes at the Footprint and Piggy Bank from optical surveys using a remotely operated vehicle (ROV). NOAA Tech. Memo. NMFS-SWFSC-521, $32 \mathrm{p}$.

Stoner, A. W., C. H. Ryer, S. J. Parker, P. J. Auster, and

W. W. Wakefield.

2008. Evaluating the role of fish behavior in surveys conducted with underwater vehicles. Can. J. Fish. Aquat. Sci. 65:1230-1243. Crossref

Thanopoulou, Z., M. Sini, K. Vatikiotis, C. Katsoupis, P. G. Dimitrakopoulos, and S. Katsanevakis.

2018. How many fish? Comparison of two underwater visual sampling methods for monitoring fish communities. PeerJ 6:e5066. Crossref
Trenkel, V. M., and P. Lorance.

2011. Estimating Synaphobranchus kaupii densities: contribution of fish behaviour to differences between bait experiments and visual strip transects. Deep-Sea Res., I 58:63-71. Crossref

Trenkel, V. M., P. Lorance, and S. Mahévas.

2004a. Do visual transects provide true population density estimates for deepwater fish? ICES J. Mar. Sci. 61:10501056. Crossref

Trenkel, V. M., R. I. C. C. Francis, P. Lorance, S. Mahévas, M.-J. Rochet, and D. M. Tracey.

2004b. Availability of deep-water fish to trawling and visual observation from a remotely operated vehicle (ROV). Mar. Ecol. Prog. Ser. 284:293-303. Crossref

Uiblein, F., P. Lorance, and D. Latrouite.

2003. Behaviour and habitat utilisation of seven demersal fish species on the Bay of Biscay continental slope, NE Atlantic. Mar. Ecol. Prog. Ser. 257:223-232. Crossref

Uzmann, J. R., R. A. Cooper, R. B. Theroux, and R. L. Wigley. 1977. Synoptic comparison of three sampling techniques for estimating abundance and distribution of selected megafauna: submersible vs camera sled vs otter trawl. Mar. Fish. Rev. 39(12):11-19.

Watson, A. C., L. A. Siemann, and R. T. Hanlon.

2014. Dynamic camouflage by Nassau groupers Epinephelus striatus on a Caribbean coral reef. J. Fish Biol. 85:16341649. Crossref

Whitmarsh, S. K., P. G. Fairweather, and C. Huveneers.

2017. What is big BRUVver up to? Methods and uses of baited underwater video. Rev. Fish Biol. Fish. 27:53-73. Crossref

Williams, K., C. N. Rooper, A. De Robertis, M. Levine, and R. Towler. 2018. A method for computing volumetric fish density using stereo cameras. J. Exp. Mar. Biol. Ecol. 508:21-26. Crossref

Wood, S. N.

2011. Fast stable restricted maximum likelihood and marginal likelihood estimation of semiparametric generalized linear models. J. R. Stat. Soc., B 73:3-36. Crossref

Yoklavich, M. M., M. S. Love, and K. A. Forney.

2007. A fishery-independent assessment of an overfished rockfish stock, cowcod (Sebastes levis), using direct observations from an occupied submersible. Can. J. Fish. Aquat. Sci. 64:1795-1804. Crossref

Yoklavich, M., J. Reynolds, and D. Rosen.

2015. A comparative assessment of underwater visual survey tools: results of a workshop and user questionnaire. NOAA Tech. Memo. NMFS-SWFSC-547, 34 p. 